\title{
Supplement to: Reconciling the surface temperature-surface mass balance relationship in models and ice cores in Antarctica over the last two centuries
}

Marie G.P. Cavitte et al.

\section{Supplementary Material}

Figures S1, S2, S3 and S4 show the correlation between $\delta^{18} \mathrm{O}$ and SMB, and SMB and SAT for each iGCM model at its original spatial resolution, over the 1871-2000 AD and 1961-2000 AD time intervals. Fig.S5 shows the spatial distribution of the ice cores used for the SMB-SAT and $\delta^{18}$ O-SMB correlations. Fig.S6 shows the 5-yearly SMB-SAT correlation averaged over the

5 four iGCMs. Fig.S7 show the correlation of SMB and SAT at the seasonal timescale. Fig.S8 show the correlation of SMB and SAT at the monthly timescale. Fig.S9 shows the RACMO2.3 (Van Wessem et al., 2018) wind strength and direction averaged over the entire period (1979-2016 AD). 


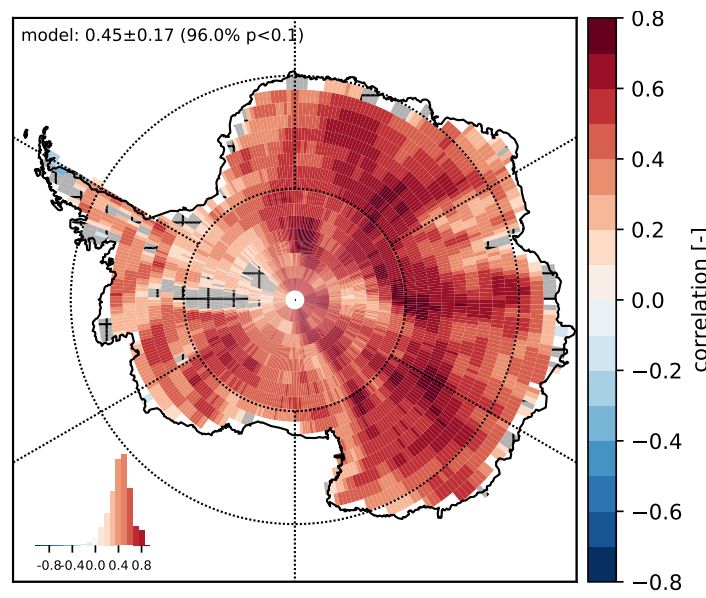

(a) ECHAM5-wiso

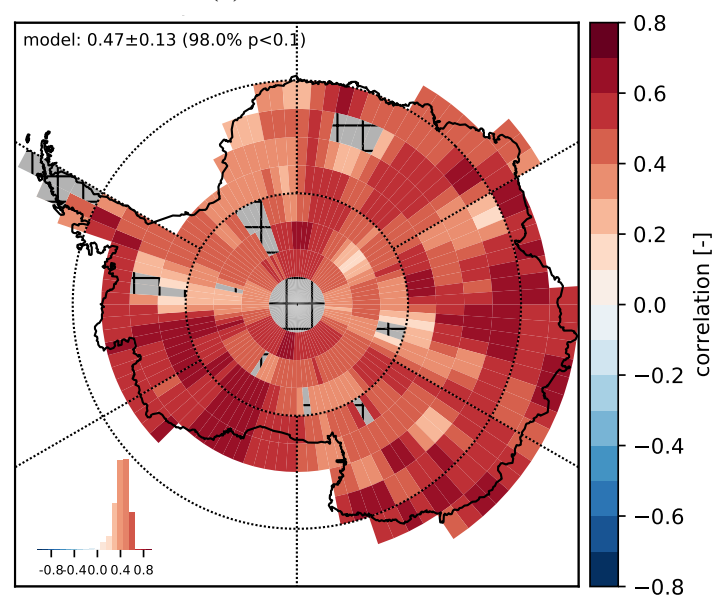

(c) iHadCM3

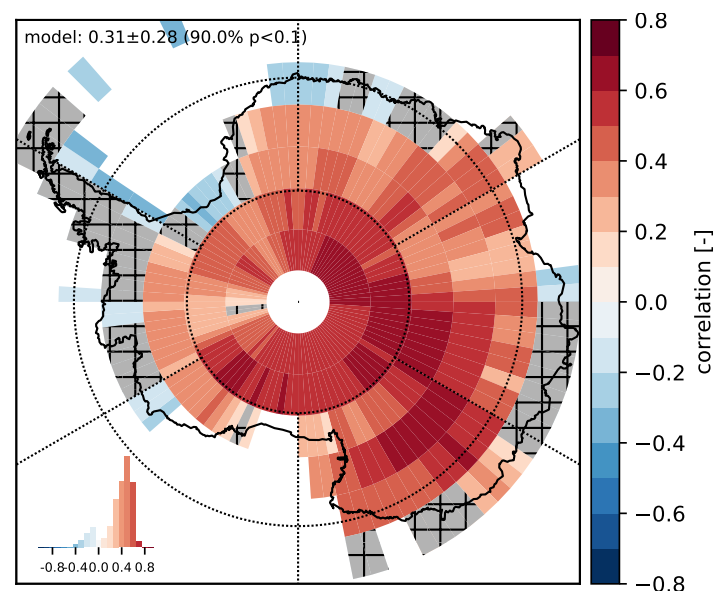

(b) ECHAM5-MPI-OM

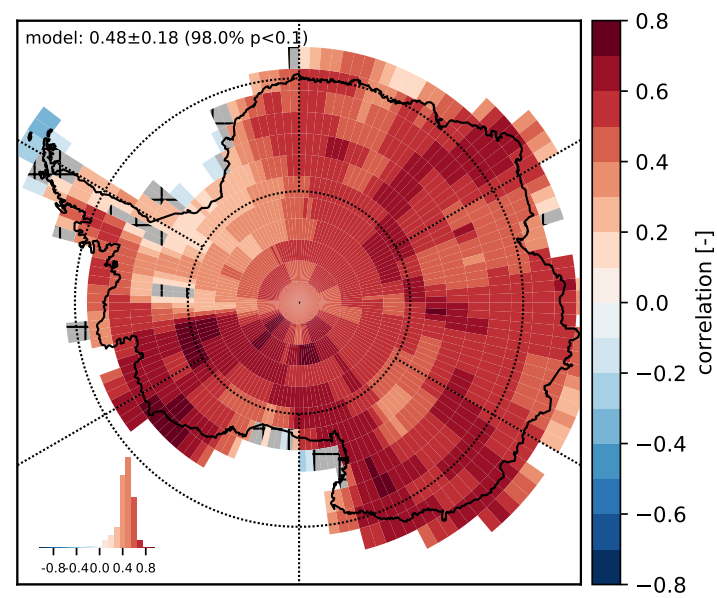

(d) iCESM1

Figure S1. Annual correlation between $\delta^{18} \mathrm{O}$ and SMB over 1871-2000 AD for each isotopic GCM. Statistically insignificant areas (p > 0.1) are hashed in grey. The histogram displays the distribution of correlation values. Continent-wide correlation mean, standard deviation and percentage of model area with $\mathrm{p}<0.1$ are provided on each panel.

\section{References}

Van Wessem, J. M., Jan Van De Berg, W., Noël, B. P., Van Meijgaard, E., Amory, C., Birnbaum, G., Jakobs, C. L., Krüger, K., Lenaerts, J.,

Lhermitte, S., et al.: Modelling the climate and surface mass balance of polar ice sheets using RACMO2: Part 2: Antarctica (1979-2016),

The Cryosphere, 12, 1479-1498, 2018. 


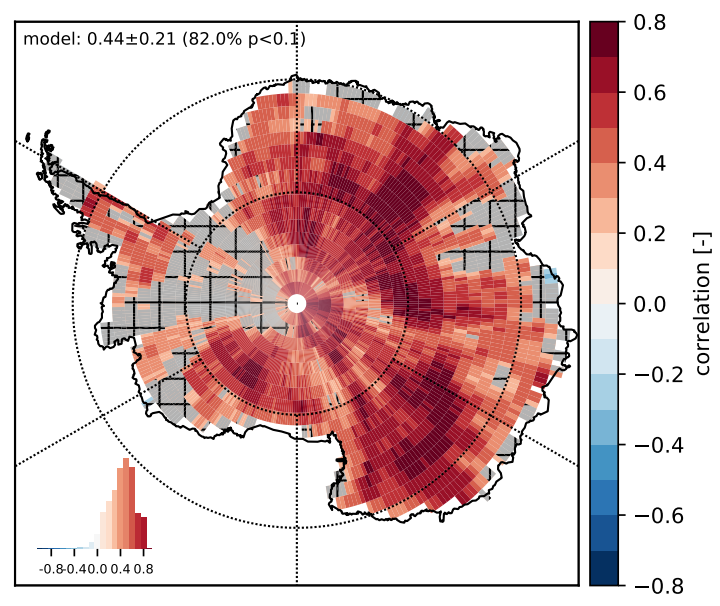

(a) ECHAM5-wiso

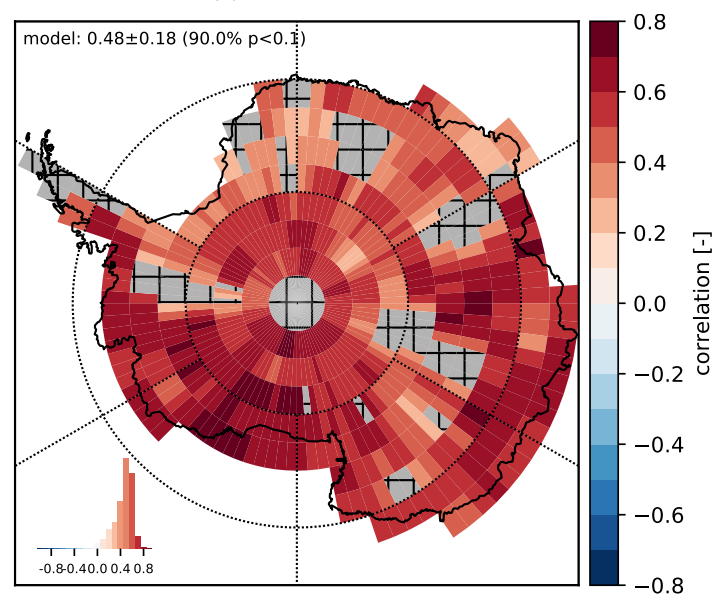

(c) iHadCM3

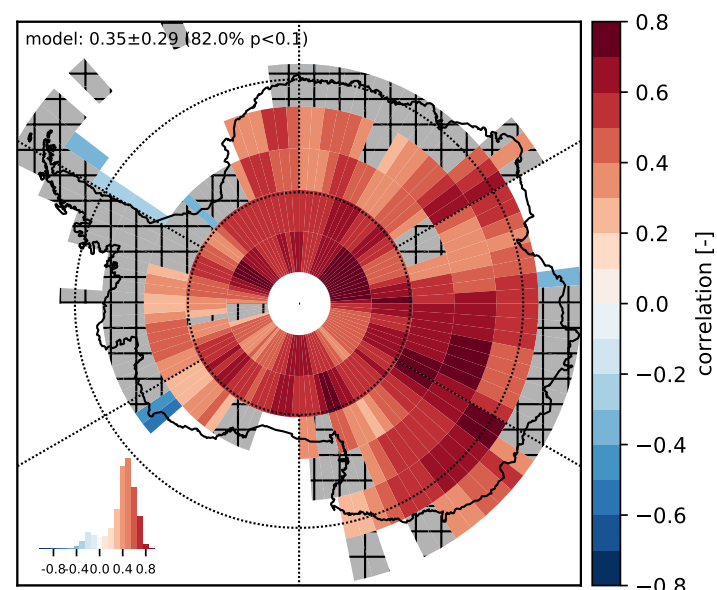

(b) ECHAM5-MPI-OM

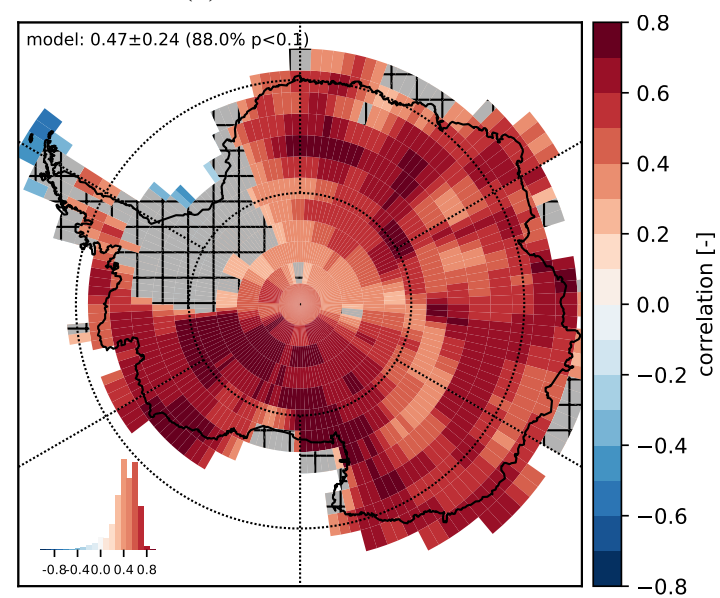

(d) iCESM1

Figure S2. Annual correlation between $\delta^{18} \mathrm{O}$ and SMB over 1961-2000 AD for each isotopic GCM. Statistically insignificant areas (p > 0.1) are hashed in grey. The histogram displays the distribution of correlation values. Continent-wide correlation mean, standard deviation and percentage of model area with $\mathrm{p}<0.1$ are provided on each panel. 


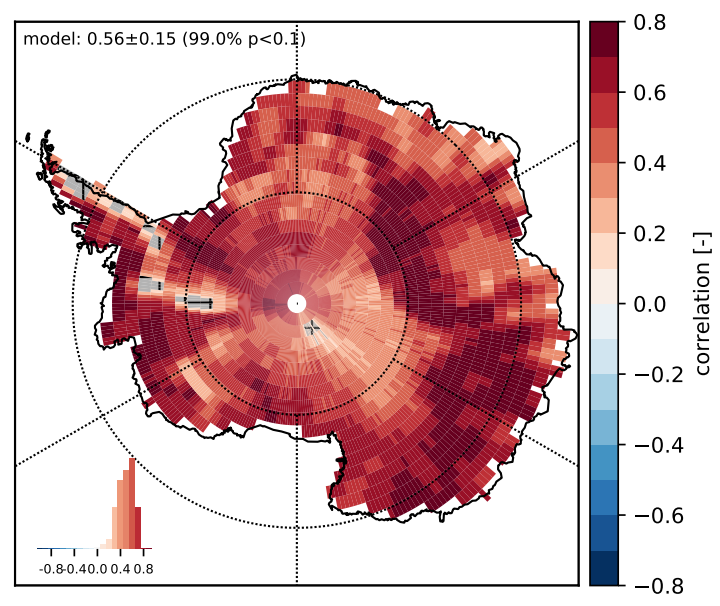

(a) ECHAM5-wiso

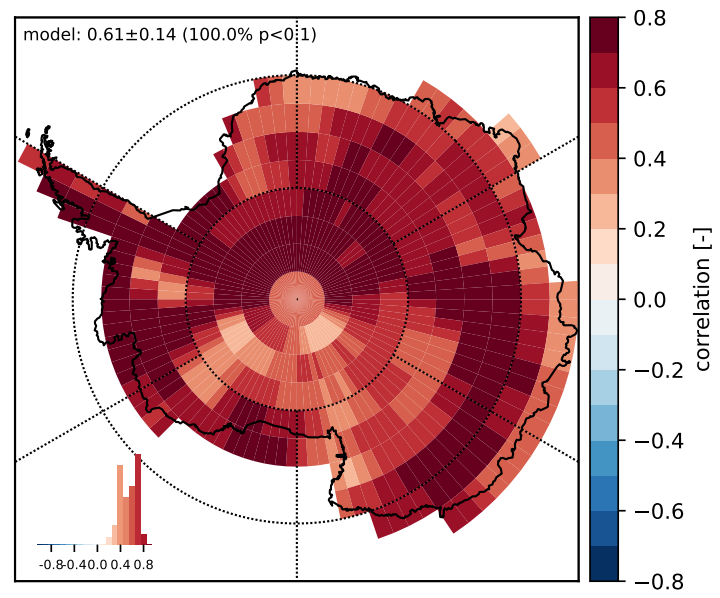

(c) iHadCM3

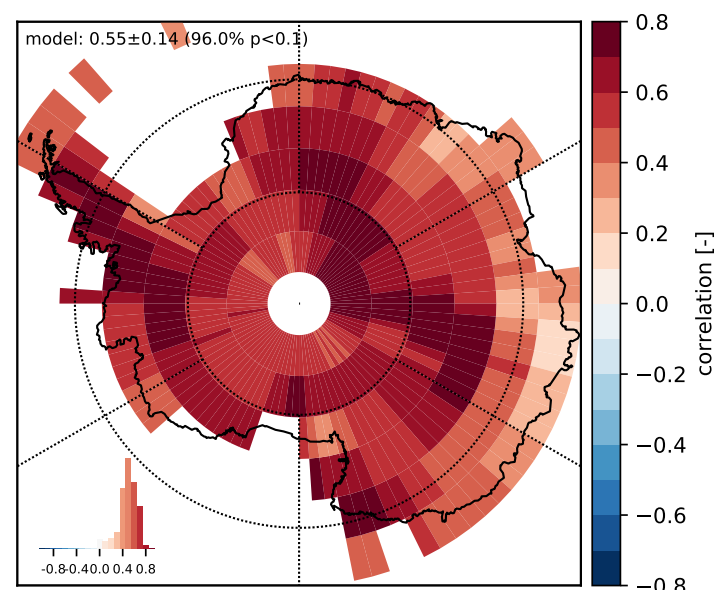

(b) ECHAM5-MPI-OM

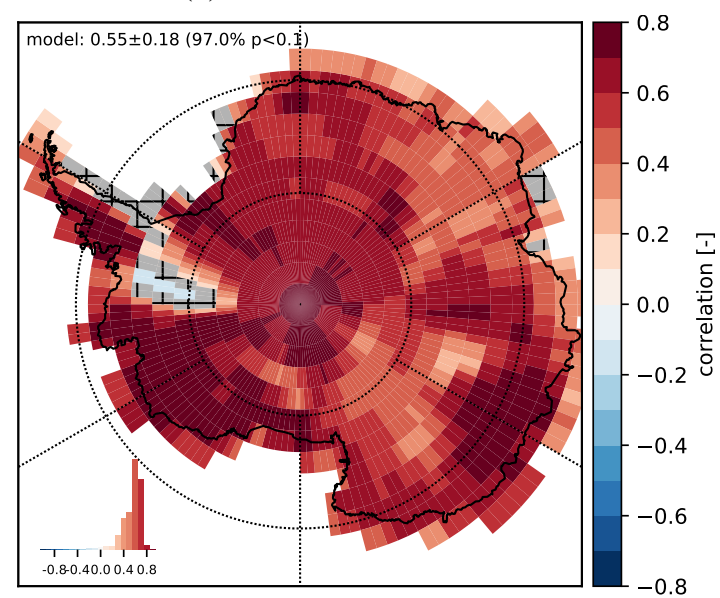

(d) iCESM1

Figure S3. Annual correlation between SMB and SAT over 1871-2000 AD for each isotopic GCM. Statistically insignificant areas (p > 0.1) are hashed in grey. The histogram displays the distribution of correlation values. Continent-wide correlation mean, standard deviation and percentage of model area with $\mathrm{p}<0.1$ are provided on each panel. 


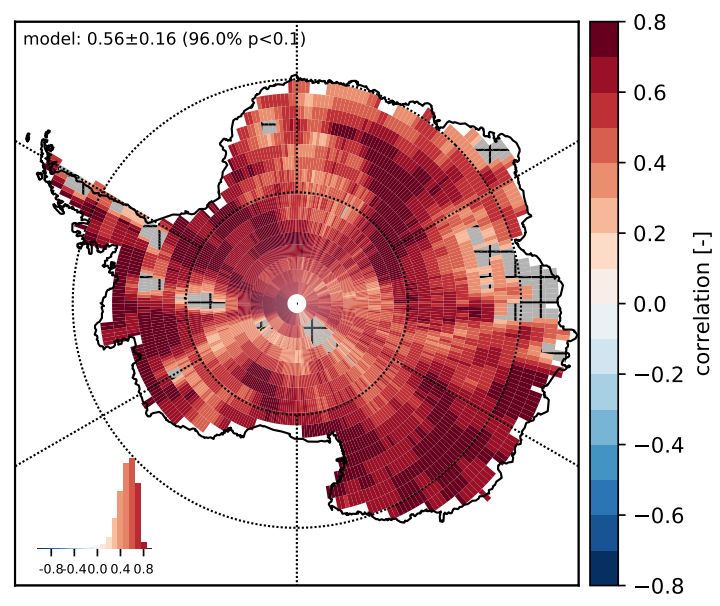

(a) ECHAM5-wiso

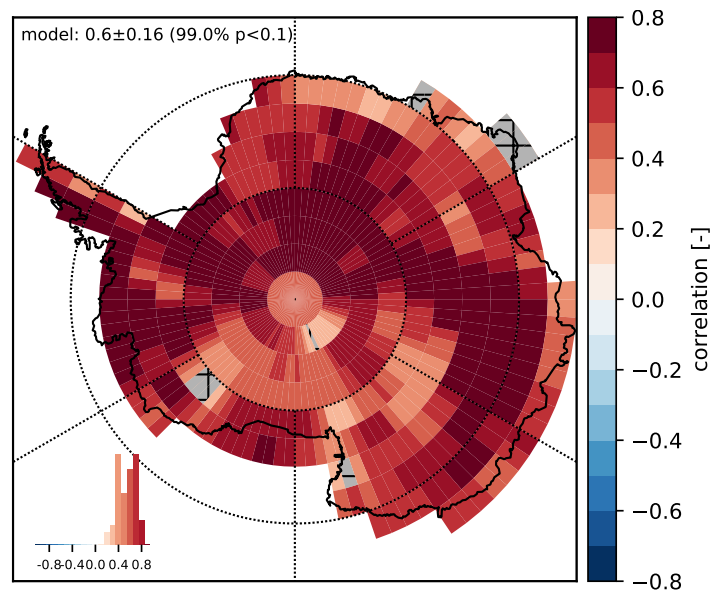

(c) iHadCM3

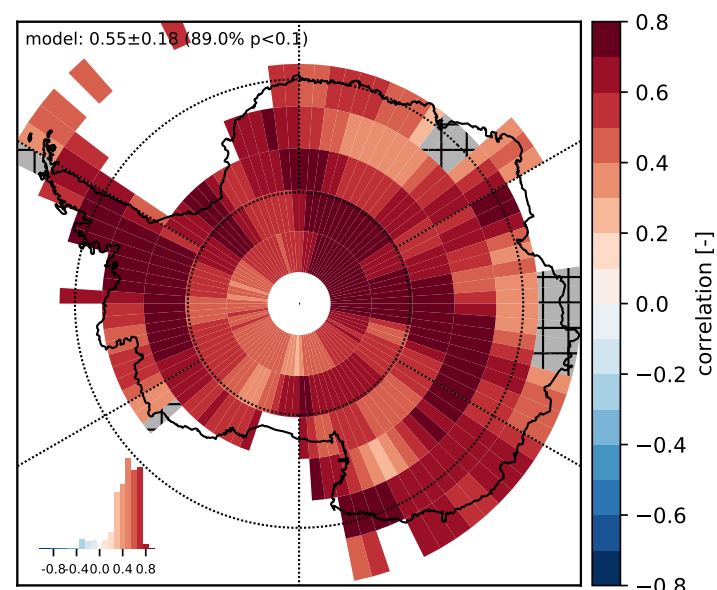

(b) ECHAM5-MPI-OM

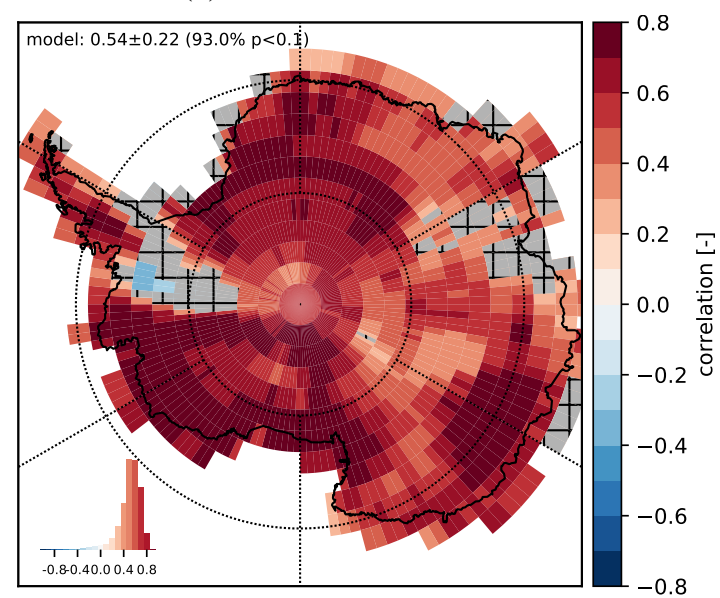

(d) iCESM1

Figure S4. Annual correlation between SMB and SAT over 1961-2000 AD for each isotopic GCM. Statistically insignificant areas (p > 0.1) are hashed in grey. The histogram displays the distribution of correlation values. Continent-wide correlation mean, standard deviation and percentage of model area with $\mathrm{p}<0.1$ are provided on each panel. 

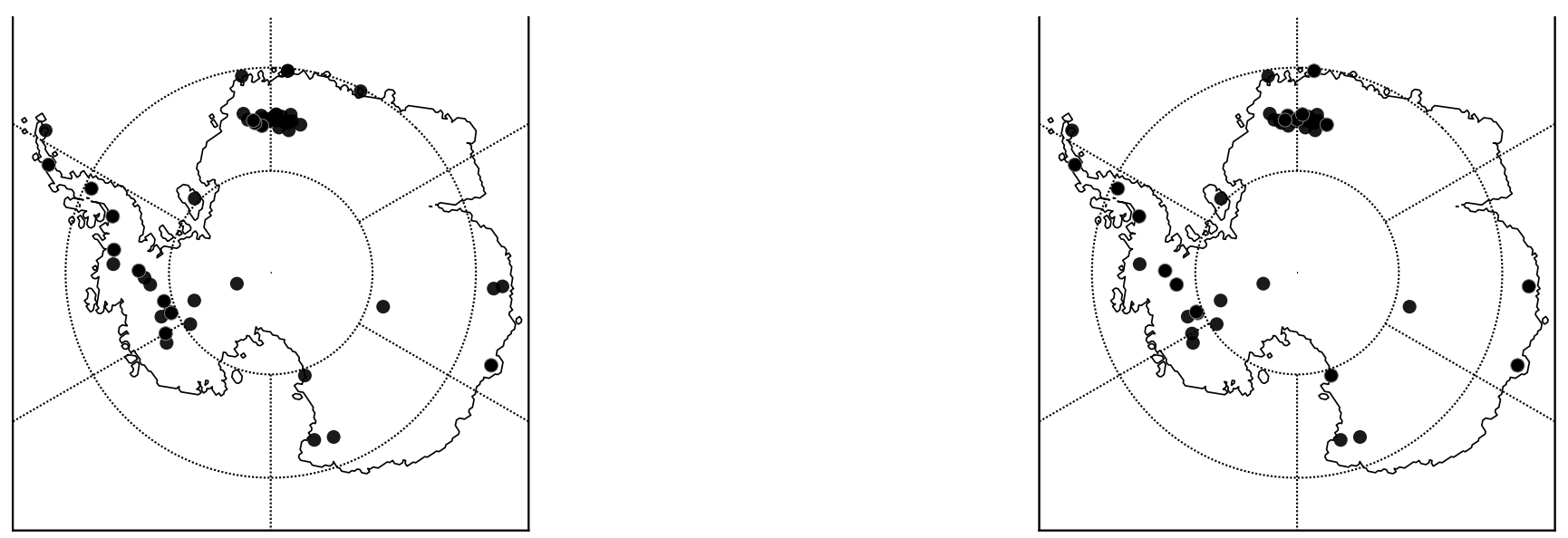

Figure S5. Spatial distribution of the ice cores used in this study for correlations: (left) between SMB and SAT over 1958-2010 AD (total = 58) and (right) between $\delta^{18} \mathrm{O}$ and SMB over 1871-2010 AD (total = 53).

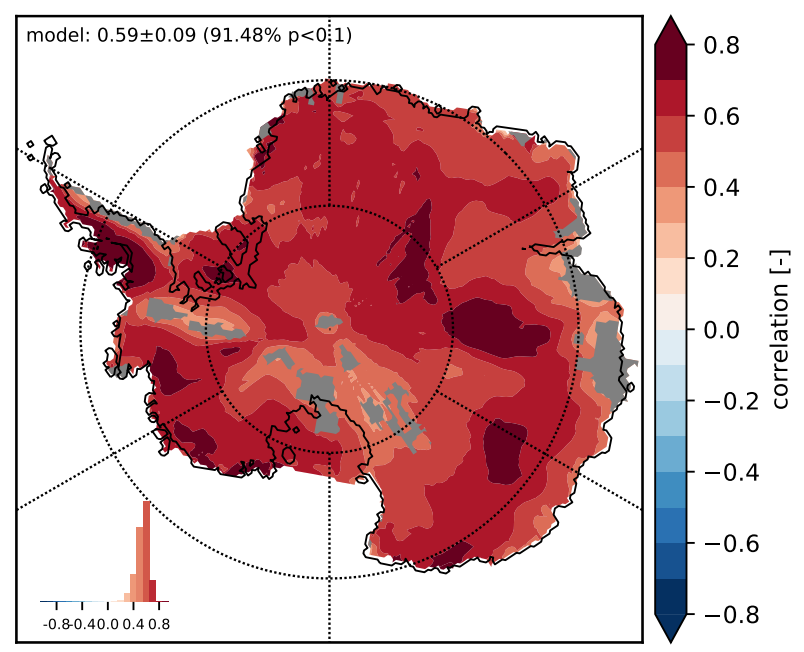

Figure S6. 5-yearly correlation between SMB and SAT, averaged over all four isotopic GCMs over 1871-2000 AD. Statistically insignificant areas $(\mathrm{p}>0.1)$ are hashed in grey. The histogram displays the distribution of correlation values for each panel. Averaged region-wide correlation mean, standard deviation and percentage of model area with $\mathrm{p}<0.1$ are provided on the figure. 


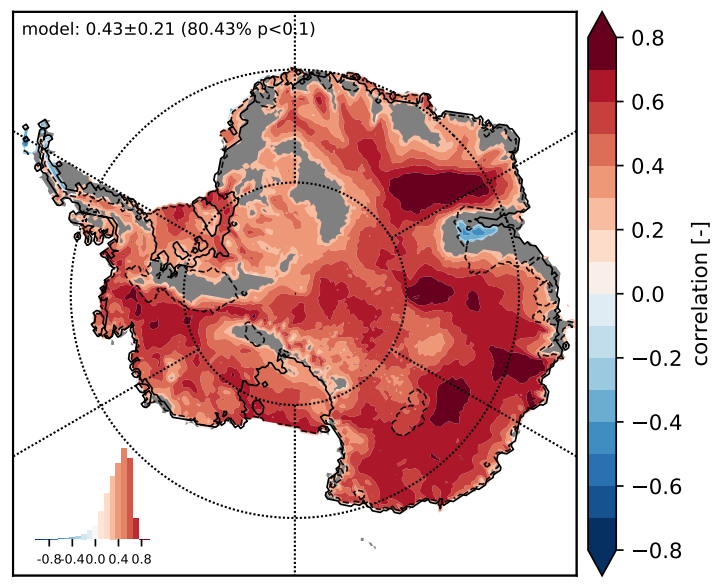

(a) SMB-SAT DJF

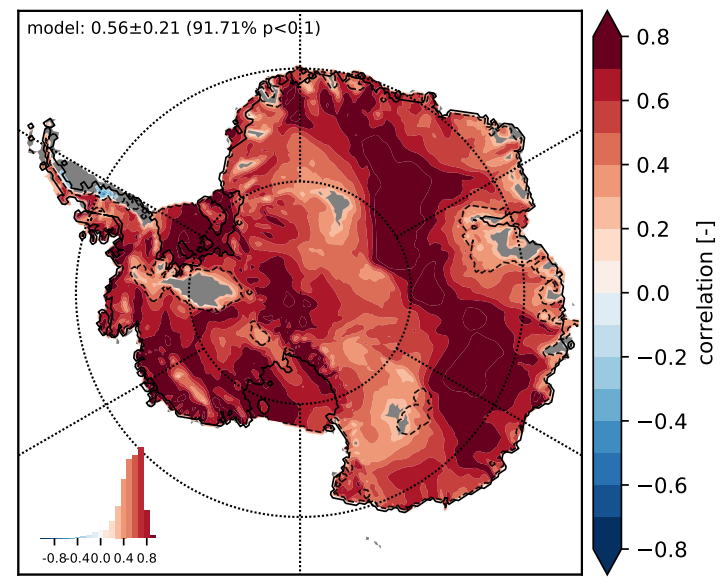

(b) SMB-SAT JJA

Figure S7. Annual correlation between SMB and SAT for (a) austral summers (DJF) and (b) austral winters only (JJA) using RACMO27 model simulations over 1979-2016 AD. Statistically insignificant areas ( $>$ > 0.1) are in grey. Dashed black lines outline the areas with a weak SMB-SAT correlation from Fig.2 in the main manuscript. The histogram displays the distribution of correlation values for each panel. Region-wide correlation mean, standard deviation and percentage of model area with $\mathrm{p}<0.1$ are provided on each panel.

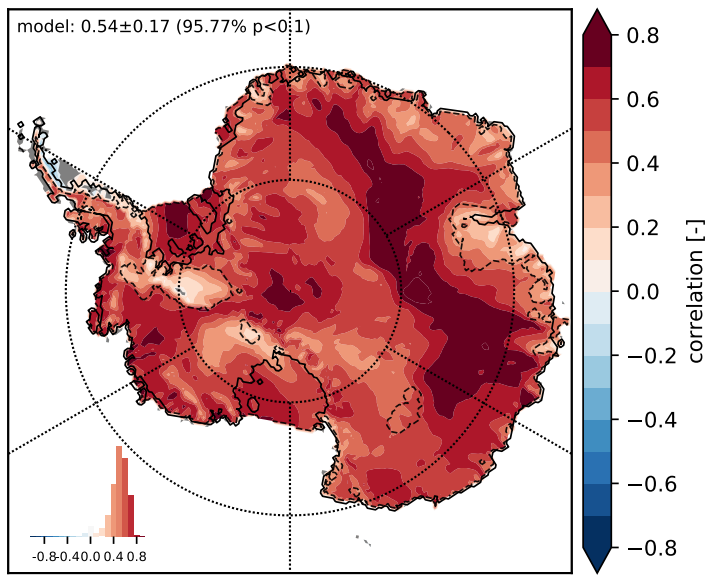

Figure S8. Monthly correlation between SMB and SAT using RACMO27 simulations over 1979-2016 AD. Dashed black lines outline the areas with a weak SMB-SAT correlation from Fig. 2 in the main manuscript. The histogram displays the distribution of correlation values for each panel. Region-wide correlation mean, standard deviation and percentage of model area with $\mathrm{p}<0.1$ are provided on the figure. 


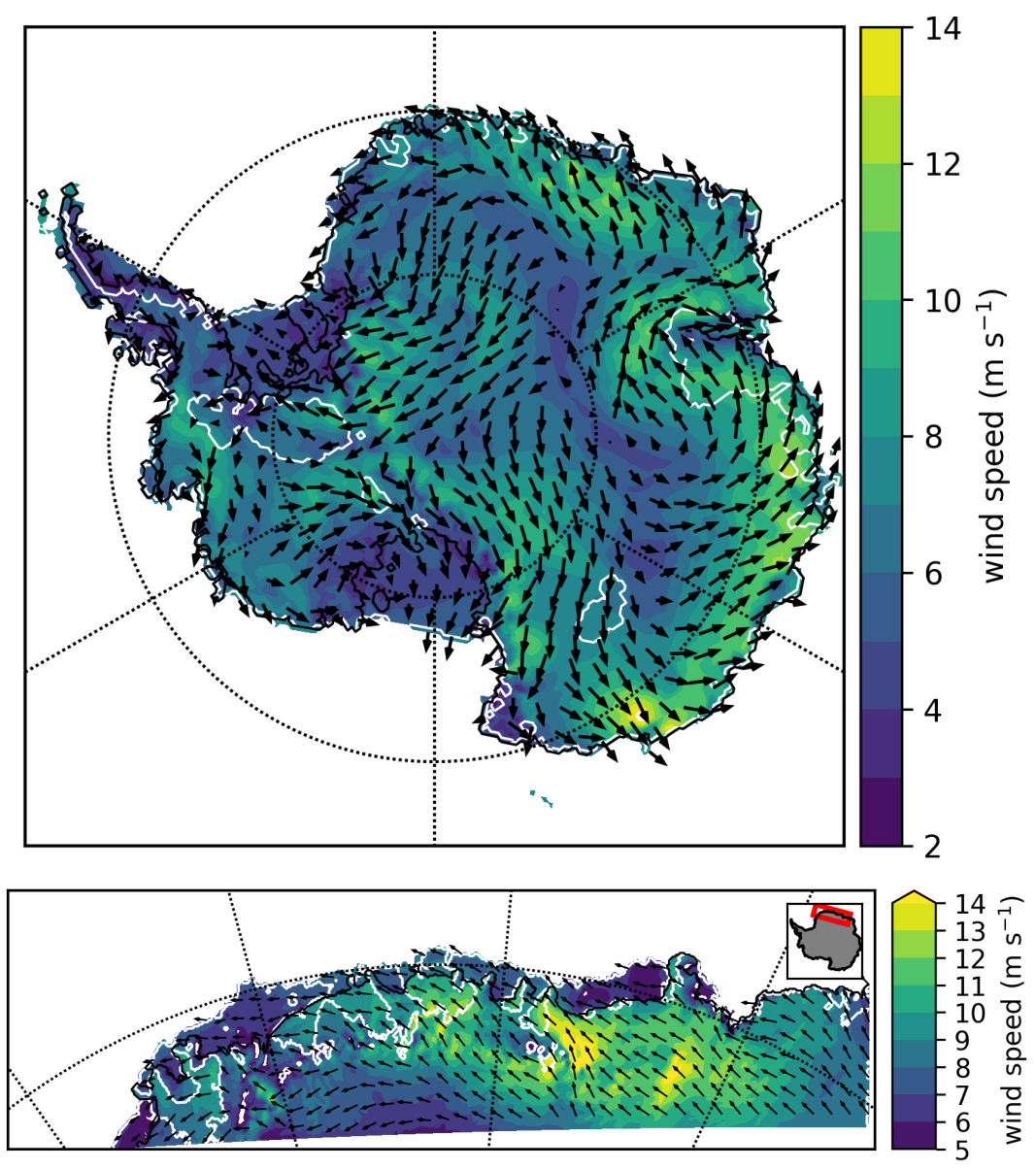

Figure S9. Mean wind speed and direction for the AIS based on (top) RACMO27 and (bottom) RACMO5 simulations over 1979-2016 AD. White lines outline the areas with a weak SMB-SAT correlation from Fig.2 in the main manuscript. 